\title{
Germinação de sementes de Urochloa ruziziensis em função da disponibilidade hídrica do substrato e teor de água das sementes ${ }^{1}$
}

\author{
Tathiana Elisa Masetto 2 , Dágon Manoel Ribeiro ${ }^{3}$, Rodrigo Kelson Silva Rezende ${ }^{4}$
}

\begin{abstract}
Germination of Urochloa ruziziensis seeds according to substrate water availability and seeds moisture content

Water stress and seed water content can affect the first germination stages and disturb the full pasture establishment. This study aimed at evaluating the effect of substrate water availability and seed water content on the germination of Urochloa ruziziensis seeds, as well as verifying any harmful effect of seed imbibition. The treatments consisted of seeds with $9.5 \%, 11.3 \%$ and $14.6 \%$ of moisture content, subjected to substrate water availability simulated with aqueous solutions of polyethylene glycol 6000 (PEG 6000) of 0.0 MPa (PubMed control), -0.1 MPa, -0.2 MPa, -0.3 MPa and -0.4 MPa. The following characteristics were used to evaluate the seeds physiological quality: germination percentage and first counting, aerial and primary root length and seedlings fresh weight. The experimental design was completely randomized, with four replications of 50 seeds. All the evaluated characteristics were negatively influenced by the water potentials reduction, however, the $U$. ruziziensis seeds with $11.3 \%$ and $14.6 \%$ of moisture content showed a higher germination rate and seedlings growth at low water availability. Despite the reduction in the indexes evaluated for water deficiency, the damage extension in seeds was determined by seeds moisture content and water stress severity.
\end{abstract}

KEY-WORDS: Tropical forage; polyethylene glycol; seeds physiologic quality.

\section{INTRODUÇ̃̃O}

O gênero Urochloa (syn. Brachiaria), nativo das savanas tropicais africanas, é um importante insumo forrageiro, principalmente no Brasil. Embora o potencial forrageiro das braquiárias tenha sido reconhecido há cerca de 40 anos, o maior impacto das espécies foi sentido somente nas últimas três décadas,

\section{RESUMO}

O estresse hídrico e o grau de umidade das sementes podem afetar as primeiras fases da germinação e prejudicar o pleno estabelecimento de pastagens. Objetivou-se avaliar o efeito de potenciais hídricos do substrato e do teor de água das sementes, na germinação de sementes de Urochloa ruziziensis, e verificar a ocorrência de possíveis danos, por embebição, às sementes. Os tratamentos foram constituídos de sementes com teores de água de $9,5 \% ; 11,3 \%$; e 14,6\%, submetidas aos seguintes potenciais hídricos no substrato, simulados com soluções aquosas de polietilenoglicol 6000 (PEG 6000): 0,0 MPa (PubMed controle); -0,1 MPa; -0,2 MPa; -0,3 MPa; e -0,4 MPa. As seguintes características foram utilizadas para avaliar o potencial fisiológico das sementes: percentagem e primeira contagem de germinação, comprimento da parte aérea e raiz e massa fresca das plântulas. Utilizou-se o delineamento inteiramente casualizado, com quatro repetições de 50 sementes. Todas as características avaliadas foram influenciadas negativamente pela redução nos potenciais hídricos, entretanto, as sementes de U. ruziziensis com teores de água de $11,3 \%$ e 14,6\% apresentaram maior germinação e crescimento de plântulas, em condições de diminuição de disponibilidade hídrica. Apesar da redução nos índices avaliados com a deficiência hídrica, a extensão dos danos em sementes foi determinada pelo teor de água das sementes e pela severidade do estresse hídrico.

PALAVRAS-CHAVE: Forrageira tropical; polietilenoglicol; qualidade fisiológica de sementes.

quando duas cultivares selecionadas diretamente de germoplasma de ocorrência natural foram extensivamente plantadas na América Latina.

De acordo com Risso-Pascotto et al. (2005), embora o gênero Urochloa compreenda, aproximadamente, 100 espécies com grandes diferenças morfológicas e fenológicas intraespecíficas, somente algumas espécies têm sido exploradas, como a

1. Trabalho recebido em fev./2013 e aceito para publicação em out./2013 ( $\mathrm{n}^{\mathrm{o}}$ registro: PAT 22634).

2. Universidade Tecnológica Federal do Paraná (UTFPR), Departamento de Ciências Agrárias, Pato Branco, PR, Brasil. E-mail:tmasetto@gmail.com.

3. Universidade Federal da Grande Dourados (UFGD), Faculdade de Ciências Biológicas e Ambientais, Dourados, MS, Brasil. E-mail: dagonribeiro@hotmail.com.

4. Universidade Federal da Grande Dourados (UFGD), Faculdade de Ciências Agrárias, Dourados, MS, Brasil. E-mail: rkelson@ufgd.edu.br. 
U. brizantha, U. decumbens e U. humidicola. Entretanto, a U. ruziziensis tem importantes características para pastagem e para o cruzamento interespecífico.

A $U$. ruziziensis não se desenvolve bem em solos alagadiços, adaptando-se melhor a solos bem drenados e com boa fertilidade. Na Amazônia, esta espécie tem sido utilizada na formação de pastagens de "terra firme" e para evitar efeitos resultantes da erosão, em regiões de declividade mais acentuada (Embrapa 2012).

Existem relatos de que esta espécie apresenta razoável tolerância ao frio, baixa tolerância à umidade e média tolerância à seca, bem como excelente velocidade de recuperação após as primeiras chuvas, no final da seca, o que lhe dá bom destaque para plantio nas regiões Nordeste e Centro-Oeste do Brasil. Por apresentar sistema radicular profundo e propiciar maior acúmulo de carbono, em relação ao sistema radicular da soja e do trigo, que são mais superficiais, a $U$.ruziziensis tem sido recomendada no sistema plantio direto, para formação de palhada e proteção do solo (Pariz et al. 2010).

Normalmente, as forrageiras tropicais apresentam problemas na produção de sementes, o que tem resultado em baixos rendimentos das colheitas, quando comparadas com as espécies de clima temperado (Machado et al. 2012). Apesar de ser estolonífera e ter boa capacidade de rebrota, para iniciar a formação de pastagem com $U$. ruziziensis, o meio utilizado é a semeadura direta. Entretanto, existem poucas informações sobre o comportamento de suas sementes com diferentes teores de água e em condições de disponibilidade hídrica reduzida, o que pode comprometer a germinação das sementes e o estabelecimento adequado do estande.

De acordo com Donaldson (1996), a fisiologia das plantas varia consideravelmente em estresse hídrico, durante o desenvolvimento da cultura, e as sementes devem ser capazes de absorver água e emergir em áreas com deficiência hídrica e alta temperatura. $\mathrm{O}$ estresse hídrico diminui a velocidade de emergência e de desenvolvimento da plântula, afetando o número de folhas, sementes por planta, tamanho e massa de sementes.

Garcia et al. (1998) verificaram que o decréscimo do potencial hídrico diminuiu a percentagem de germinação e aumentou o número de dias para a germinação inicial e total de sementes de $B$. brizantha cv. Marandu. Neste estudo, as sementes apresentaram germinação nula, sob potencial de -1,2 MPa com manitol, e foi concluído que o emprego de soluções, para predizer o desempenho de germinação em solos, deve ser empregado com cautela, uma vez que as alterações do potencial hídrico em meio líquido são mais rápidas do que em solos.

A atividade fisiológica das sementes está diretamente relacionada ao seu teor de água. Segundo Marcos Filho (2005), os teores de água variam de acordo com a espécie e composição química da semente, porém, as faixas de umidade relativa do ar que determinam estes teores são semelhantes para as diferentes espécies, independentemente do tipo de tecido e sua composição.

Sob diferentes níveis de hidratação dos tecidos, a água possui propriedades físicas distintas. Quando o teor de água e o potencial hídrico são elevados, a água tem propriedades características de uma solução diluída e, à medida em que o tecido desidrata, a água passa a exibir características de solução concentrada, em que a interação água/soluto se distancia da ideal. A redução mais drástica de quantidade de água torna a solução ainda mais concentrada, acentuando sua viscosidade e aproximando-a do estado vítreo (glassy). Finalmente, sob grau de umidade muito baixo, a água se torna fortemente ligada à superfície de macromoléculas, com mobilidade extremamente reduzida (Marcos Filho 2005).

O nível de hidratação das sementes também está associado à intensidade da ocorrência de injúrias, durante a embebição para a germinação. As sementes muito secas (teor de água inferior a $11 \%$ - base úmida) são mais afetadas quando em contato com matrizes apresentando alta disponibilidade hídrica. Assim, a diversidade de relações água/sementes, influenciando vários aspectos do desempenho, determina a necessidade da condução de pesquisas básicas e aplicadas, para a elucidação de fenômenos, processos ou procedimentos tecnológicos, como os estudos dos processos de germinação e deterioração, efeitos de injúrias mecânicas e processos de secagem e armazenamento (Marcos Filho 2005).

Estudos relacionados à fisiologia e manejo de sementes de $U$. ruziziensis ainda são incipientes na literatura e, até o momento, não foram encontrados relatos sobre possíveis efeitos de tensões osmóticas negativas em sementes, com variações nos graus de umidade. Diante disto, objetivou-se, com este trabalho, avaliar o efeito de diferentes potenciais hídricos do substrato e de teores de água das sementes na germinação de sementes de U. ruziziensis. 


\section{MATERIAL E MÉTODOS}

O experimento foi conduzido no Laboratório de Sementes da Faculdade de Ciências Agrárias da Universidade Federal da Grande Dourados (22 ${ }^{\circ} 11^{\prime} 43^{\prime \prime}$ S, 54 $56^{\circ} 08^{\prime \prime} \mathrm{W}$ e altitude de $458 \mathrm{~m}$ ). As sementes de $U$. ruziziensis utilizadas pertenciam a um único lote e foram produzidas em Mato Grosso do Sul, em 2010.

Para avaliar o efeito do teor de água das sementes, associado à disponibilidade hídrica do substrato, obtiveram-se sementes com diferentes teores de água $(9,5 \% ; 11,3 \%$; e 14,6\%), adotando-se o procedimento de umedecimento artificial (Marcos Filho 2005) e empregando-se caixas plásticas do tipo "gerbox", contendo $40 \mathrm{~mL}$ de água destilada no fundo e telas de alumínio com 240 sementes distribuídas sobre as telas. As caixas foram tampadas e levadas para câmaras do tipo Biochemical Oxygen Demand (B.O.D.), sob temperatura alternada de $20-35^{\circ} \mathrm{C}$, e, durante a permanência das mesmas na câmara, foi realizado, periodicamente, o monitoramento da massa úmida das sementes em hidratação durante 24 e 48 horas. $O$ teor de água das sementes foi determinado pelo método da estufa a $103 \pm 2^{\circ} \mathrm{C}$, durante 24 horas (Brasil 2009), com quatro repetições de $2,0 \mathrm{~g}$. Inicialmente, as sementes apresentaram 9,5\% de teor de água e, após o umedecimento artificial durante 24 e 48 horas, apresentaram 11,3\% e 14,6\% de teor de água, níveis, estes, considerados no experimento.

Para avaliar o efeito de diferentes disponibilidades hídricas do substrato na germinação de U. ruziziensis, foram utilizadas soluções aquosas de polietilenoglicol (PEG 6000), com potenciais de -0,1 MPa; -0,2 MPa; -0,3 MPa; e -0,4 MPa, cuja quantidade de PEG 6000 foi calculada a partir da equação proposta por Michel \& Kaufmann (1973): $\psi \mathrm{OS}=-\left(1,18 \times 10^{-2}\right) \mathrm{C}-\left(1,18 \times 10^{-4}\right) \mathrm{C} 2+(2,67 \times$ $\left.10^{-4}\right) \mathrm{CT}+\left(8,39 \times 10^{-7}\right) \mathrm{C}^{2} \mathrm{~T}$, em que $\psi$ os $=$ potencial osmótico (bar); $\mathrm{C}=$ concentração (gramas de $\mathrm{PEG}$ 6000 por $\mathrm{kg}$ de água destilada $\left.{ }^{-1}\right)$ e $\mathrm{T}=$ temperatura $\left({ }^{\circ} \mathrm{C}\right)$, sendo considerada a de $25^{\circ} \mathrm{C}$.

Para a obtenção de potenciais hídricos de $-0,1 \mathrm{MPa}$; -0,2 MPa; -0,3 MPa; e -0,4 MPa, as soluções aquosas foram compostas, respectivamente, por 78,49 g; 119,54 g; 150,0 g; e 178,34 g de PEG 6000 por quilograma de água destilada. Para o preparo destas soluções, inicialmente, efetuou-se a pesagem da quantidade de PEG 6000 necessária, sendo, em seguida, misturada com água destilada, até a sua total dissolução.

Amostras de sementes pertencentes aos três teores de água foram submetidas ao teste de germinação, sob diferentes potenciais hídricos. Assim, as soluções foram utilizadas para o umedecimento do papel usado como substrato no teste de germinação sob a forma de rolo. As sementes foram mantidas em câmaras tipo B.O.D., à temperatura alternada de 20$35^{\circ} \mathrm{C}$, com fotoperíodo de 14/10 horas (luz/escuro).

$\mathrm{O}$ efeito de diferentes teores de água e disponibilidades hídricas do substrato foi avaliado pelas seguintes características:

a) Primeira contagem - realizada com o teste de germinação, de acordo com as recomendações de Brasil (2009), com quatro repetições de 50 sementes, consistindo no registro das percentagens de plântulas normais, no sétimo dia após a semeadura;

b) Germinação - avaliada aos 21 dias após a semeadura, considerando-se germinadas as sementes que emitiram plântulas normais (Brasil 2009). Os resultados foram expressos em percentagem média, com base no número de plântulas normais;

c) Comprimento da parte aérea - foram utilizadas quatro repetições de dez sementes, dispostas no terço superior do papel germitest em forma de rolo, umedecido com soluções osmóticas em quantidade equivalente a duas vezes a massa seca do substrato. Os rolos de papel foram posicionados verticalmente, formando um ângulo de $90^{\circ} \mathrm{C}$ com a bandeja da B.O.D. e mantidos à temperatura de $20-35^{\circ} \mathrm{C}$. Após 21 dias da instalação do teste, mediu-se o comprimento da parte aérea das plântulas, com régua graduada em mm, e os resultados foram expressos em cm plântula ${ }^{-1}$;

d) Comprimento da raiz primária - foram utilizadas as mesmas plântulas de cada repetição do teste anterior, sendo determinado com o auxílio de régua graduada em $\mathrm{mm}$ e os resultados expressos em cm plântula ${ }^{-1}$;

e) Comprimento total de plântulas - determinado pela medida completa do comprimento das plântulas normais, da base da raiz até o ápice da plúmula, sendo os resultados expressos em cm plântula ${ }^{-1}$;

f) Massa fresca total de plântula - obtida gravimetricamente, nas mesmas plântulas utilizadas para aferir os comprimentos da parte aérea e das raízes, sendo os resultados expressos em mg plântula ${ }^{-1}$.

O delineamento experimental foi o inteiramente casualizado, em esquema fatorial $3 \times 5$ (teores de 
água $\mathrm{x}$ potenciais hídricos), com quatro repetições de 50 sementes cada. Os dados foram submetidos à análise de regressão, para o estudo dos efeitos dos diferentes níveis de potenciais hídricos e para cada teor de água das sementes, utilizando-se o programa estatístico Sisvar (Ferreira 2000).

\section{RESULTADOS E DISCUSSÃO}

Observou-se interação entre os teores de água e os potenciais hídricos dos substratos para as características avaliadas, à exceção da primeira contagem de germinação, que foi influenciada somente pelos potenciais hídricos (Figura 1a). Sementes de
U. ruziziensis que não foram submetidas aos efeitos de potenciais hídricos negativos apresentaram 30\% de plântulas normais na primeira contagem. Entretanto, verificou-se que a redução do potencial hídrico abaixo de -0,1 MPa foi prejudicial para a formação de plântulas de $U$.ruziziensis, as quais apresentaram comportamento quadrático com elevado ajuste de regressão, sendo observado, no potencial hídrico de -1,58 MPa, redução acentuada da germinação de sementes na primeira contagem (Figura 1a). De acordo com Lopes \& Macedo (2008), os efeitos deletérios do estresse hídrico sobre as fases iniciais da germinação se iniciam nas estruturas subcelulares. O aumento da concentração de solutos no substrato determina a (a) $y=311,9047 x 2+195,5952 x+29,0880 R^{2}=99 \%$

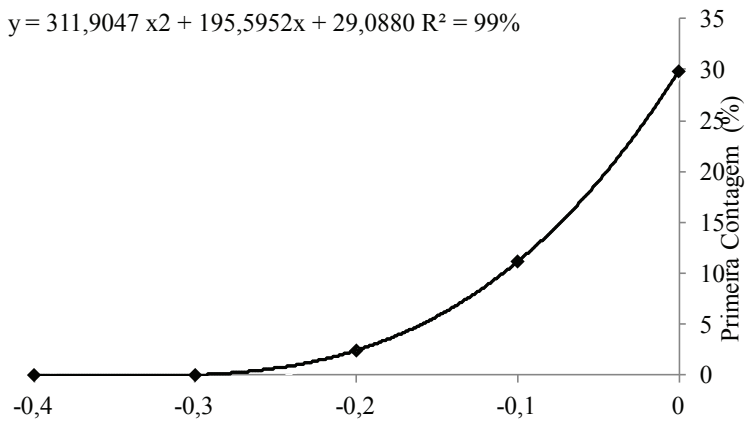

(c)

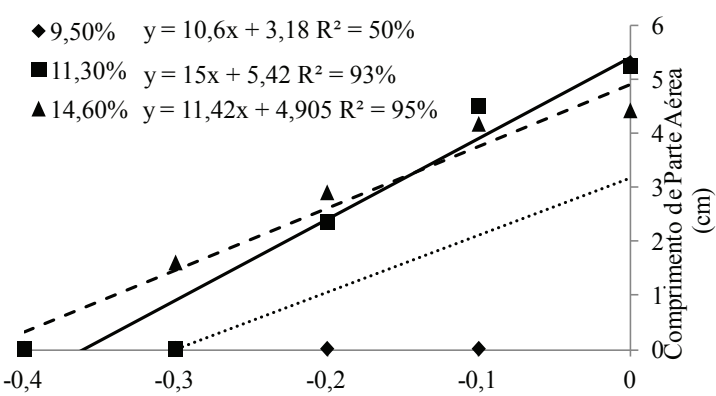

(e)

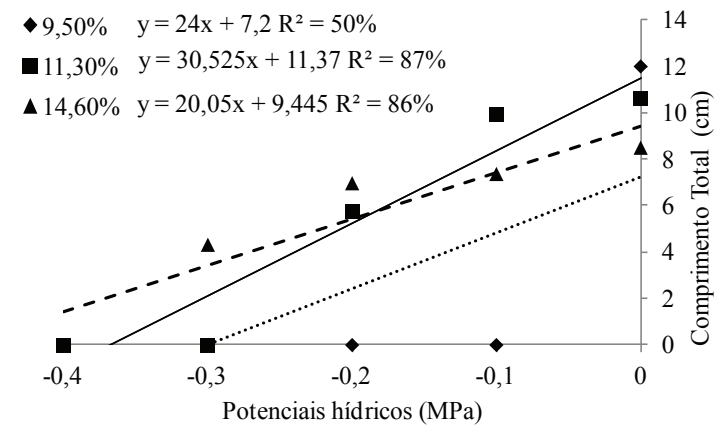

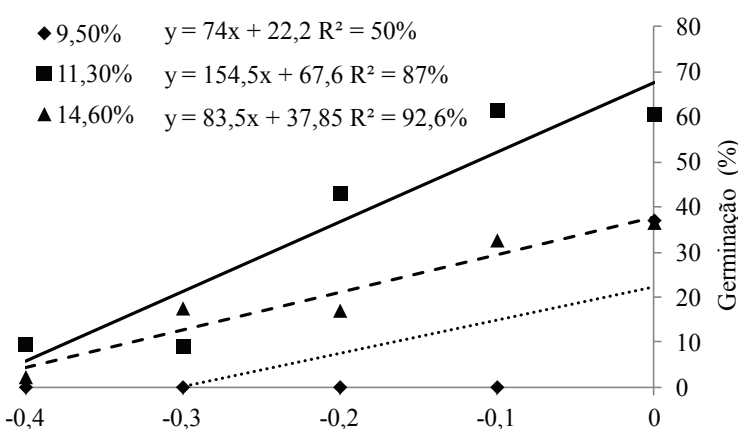

(b)

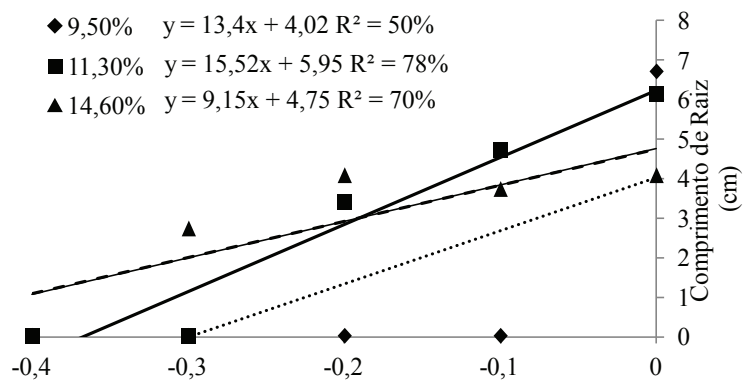

(d)

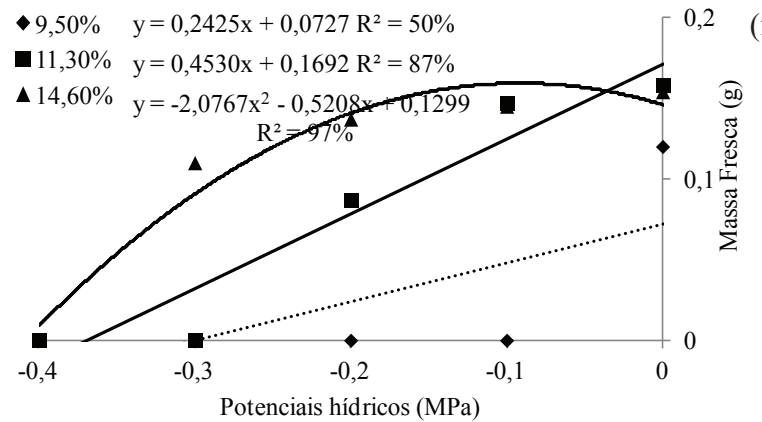

Figura 1. Primeira contagem (a), percentagem de germinação (b), comprimento da parte aérea (c), comprimento da raiz (d), comprimento total de plântulas (e) e massa fresca de plântulas (f) oriundas de sementes de Urochloa ruziziensis com diferentes graus de unidade, submetidas a diferentes potenciais hídricos do substrato (Dourados, MS, 2010). 
redução no potencial hídrico, resultando em menor capacidade de absorção de água pelas sementes, o que, geralmente, influencia na capacidade germinativa e no desenvolvimento das plântulas.

A redução dos potenciais hídricos afetou negativamente a germinação das sementes, em todos os teores de umidade estudados (Figura 1b). Verificou-se que as sementes com teores de água de $11,3 \%$ e 14,6\% apresentaram germinação superior à das sementes com 9,5\%, que foram mais sensíveis à redução do potencial hídrico de $-0,1 \mathrm{MPa}$. Deste modo, a menor tolerância à restrição hídrica foi observada em sementes de $U$. ruziziensis com teor de água de $9,5 \%$, em comparação às sementes com teores de $11,3 \%$ e $14,6 \%$.

De acordo com Neya et al. (2004), teores de água elevados nas sementes e temperaturas amenas durante a embebição podem amenizar o estresse ocasionado pela reidratação das sementes. O transporte de água é o principal mecanismo de embebição pelas sementes, para completar a germinação e, consequentemente, a emergência da plântula (Wuest 2007).

Os resultados indicam que a redução do gradiente de potencial hídrico entre o substrato e a superfície da semente provoca restrição à entrada de água através do embrião (Lopes \& Macedo 2008). A energia livre na água é elevada, sendo chamada de potencial químico da água, o qual é, frequentemente, expresso em unidades de pressão (MPa), como potencial hídrico $(\Psi)$. A água pura tem potencial químico elevado, podendo dissolver solutos e hidratar substâncias. Quando solutos são adicionados à água, esta usa a energia para dissolvê-los, diminuindo, assim, o seu potencial químico. Uma célula viva consiste de diversos compartimentos separados por membranas semipermeáveis seletivas, e canais nas membranas, formadas por proteínas, permitem a passagem da água, mas impedem a de solutos, proporcionando a diferença de gradiente de potencial hídrico entre o meio externo e o interno à membrana (Castro et al. 2004).

Resultados semelhantes aos obtidos com a germinação foram verificados para o crescimento de plântulas de U. ruziziensis (Figura 1c). O comprimento da parte aérea foi influenciado negativamente pela redução nas disponibilidades hídricas do substrato, evidenciando a sensibilidade das sementes com teor de água de 9,5\% ao estresse hídrico, em relação às sementes com teores acima de 11\% (Figura 1c).

Para o comprimento de raiz, verificou-se que, entre os potenciais hídricos de $0,0 \mathrm{MPa}$ e $-0,1 \mathrm{MPa}$, as sementes com teor de água de $11,3 \%$ foram menos sensíveis ao estresse que aquelas com 14,6\% (Figura 1d). Entretanto, com a redução dos potenciais hídricos, a partir de -0,2 MPa, verificou-se efeito menos acentuado do estresse em sementes com teor de água de 14,6\%, embora fosse verificada diminuição gradativa do crescimento de raiz para as sementes com ambos os teores de água (Figura 1d).

De acordo com Ludlow (1980), todas as espécies forrageiras tropicais apresentam, em alguma extensão, capacidade de aclimatação ao estresse hídrico. Esta estratégia envolve a manutenção do turgor e, consequentemente, a atividade metabólica e o crescimento, sendo que o principal mecanismo de manutenção é o ajuste osmótico, o qual representa uma vantagem ecológica eficiente, ao permitir o crescimento de raízes que podem explorar um volume de espaço maior do ambiente. Assim, possivelmente, para as sementes de U. ruziziensis, a característica de tolerância ao estresse hídrico moderado está associada ao teor de água das sementes.

$\mathrm{Na}$ análise do comprimento total de plântulas (Figura 1e), evidenciaram-se efeitos prejudiciais da diminuição do potencial hídrico sobre o crescimento de $U$. ruziziensis, sendo verificado que, até o potencial de - $0,1 \mathrm{MPa}$, sementes com teor de água de $11,3 \%$ originaram plântulas maiores que as sementes com teor de $9,5 \%$, sugerindo que, sob estresse moderado, ocorreu formação de plântulas com maior alongamento do que com as sementes com o teor de água original. Entretanto, potenciais hídricos abaixo de $-0,2 \mathrm{MPa}$ afetaram o crescimento total de plântulas oriundas de sementes com todos os teores de água avaliados (Figura 1e). Prejuízos decorrentes da redução dos potenciais hídricos também foram verificados para a massa fresca de plântulas de $U$. ruziziensis (Figura 1f), sendo observada redução linear da massa de plântulas em sementes com $9,5 \%$ e $11,3 \%$ de teor de água, conforme o decréscimo do potencial hídrico. Para as sementes com 14,6\%, foi delineado modelo quadrático com elevado ajuste de regressão, atingindo valor máximo de $0,125 \mathrm{~g}_{\text {plântula }}{ }^{1}$.

Nas fases iniciais de desenvolvimento da $U$. ruziziensis, podem ser verificados efeitos deletérios, devido à redução na disponibilidade hídrica, evidenciando a sensibilidade das sementes com diferentes teores de água à diminuição dos potenciais hídricos a partir de -0,1 MPa. Diversos autores destacaram a característica de sensibilidade das sementes do gênero Urochloa ao estresse hídrico (Mattos et 
al. 2005, Pereira et al. 2010), entretanto, a maioria dos relatos envolve a fase de crescimento de plantas, em detrimento das fases iniciais de germinação e estabelecimento de plântulas, que são fundamentais para o sucesso na exploração da cultura.

Devido à importância da disponibilidade hídrica para o estabelecimento da cultura, existem diversos questionamentos sobre a época de semeadura da U. ruziziensis, cujo atraso implicará em maior risco climático para o desenvolvimento no sistema de consórcio com o milho, provocando perdas devido à competição por água entre as culturas (Richart et al. 2010). Tekletsadik et al. (2004) observaram que o rendimento de $U$. ruziziensis, considerando-se a produção de grãos e de massa seca, foi afetado na estação seca. Pereira et al. (2010) observaram que, em plantas de $U$. plantaginea sob restrição hídrica (manejo hídrico de 8\%), não houve eficiência dos tratamentos herbicidas, mesmo com o uso da dose recomendada, a qual se igualou aos resultados, quando se aplicou um quarto da dose.

Plantas de $U$. brizantha submetidas ao déficit hídrico, durante 23 dias, apresentaram taxa de alongamento das lâminas foliares comprometida, e a taxa de senescência de lâminas foliares em $U$. mutica aumentou com o decréscimo do potencial hídrico no solo, denotando a maior sensibilidade destas duas espécies ao déficit hídrico (Mattos et al. 2005). Estes autores concluíram que o déficit hídrico reduziu, acentuadamente, a fotossíntese líquida em $U$. mutica e $U$. humidicola, sendo que as espécies avaliadas recuperaram suas atividades fotossintéticas normais após o déficit hídrico, mas apenas a $U$. brizantha restabeleceu o status hídrico de seus tecidos foliares.

Para as sementes de $U$. ruziziensis, a redução das disponibilidades hídricas simuladas com soluções osmóticas de PEG foi prejudicial à germinação das sementes e ao crescimento das plântulas. Vale salientar que a extensão dos danos provocados nas sementes, possivelmente, deve-se à severidade do estresse hídrico e ao teor de água de 9,5\% nas sementes.

\section{CONCLUSÕES}

1. As sementes de U. ruziziensis mostraram-se sensíveis à redução nos potenciais hídricos do substrato, a partir de $-0,1 \mathrm{MPa}$.

2. O estresse hídrico diminuiu a germinação e o crescimento de plântulas.
3. As sementes com teor de água de $9,5 \%$ foram mais sensíveis às tensões osmóticas.

4. Os prejuízos na germinação e no crescimento inicial de plântulas de $U$. ruziziensis foram causados pela severidade do estresse e pelo teor de água das sementes.

\section{REFERÊNCIAS}

BRASIL. Ministério da Agricultura, Pecuária e Abastecimento. Regras para análise de sementes. Brasília, DF: MAPA/ACS, 2009.

CASTRO, R. M.; BRADFORD, K. J.; HILHORST, H. W. M. Embebição e reativação do metabolismo. In: FERREIRA, A. G.; BORGUETTI, F. (Orgs.). Germinação: do básico ao aplicado. Porto Alegre: Artmed, 2004. p. 251-262.

DONALDSON, E. Crop traits for water stress tolerance. American Journal of Alternative Agriculture, New Jersey, v. 11, n. 2, p. 89-94, 1996.

EMPRESA BRASILEIRA DE PESQUISA AGROPECUÁRIA (Embrapa). Centro Nacional de Pesquisa em Gado de Corte. Gramineas forrageiras do gênero Brachiaria. 2012. Disponível em <http:// www.cnpgc.embrapa.br/publicacoes/ct/ct01/04especies. html\#4.5>. Acesso em: 9 jul. 2012.

FERREIRA, D. F. Sisvar: sistema para análise de variância. Lavras: UFLa, 2000.

GARCIA, R. et al. Efeito do potencial hídrico na germinação de sementes de três gramíneas forrageiras tropicais. Revista Brasileira de Zootecnia, Viçosa, v. 27, n. 1, p. 9-15, 1998.

LOPES, J. C.; MACEDO, C. M. P. Germinação de sementes de couve chinesa sob influência do teor de água, substrato e estresse salino. Revista Brasileira de Sementes, Londrina, v. 30, n. 3, p. 79-85, 2008.

LUDLOW, M. M. Stress physiology of tropical pasture plants. Tropical Grasslands, Sydney, v. 14, n. 3, p. 136145, 1980.

MACHADO, C. G. et al. Precocidade na emissão da raiz primária para avaliação do vigor de sementes de milheto. Semina: Ciências Agrárias, Londrina, v. 33, n. 2, p. 499506, 2012.

MARCOS FILHO, J. Fisiologia de sementes de plantas cultivadas. Piracicaba: Fealq, 2005.

MATTOS, J. L. S.; GOMIDE, J. A.; HUAMAN, C. A. M. Crescimento de espécies do gênero Brachiaria, sob déficit hídrico, em casa de vegetação. Revista Brasileira de Zootecnia, Viçosa, v. 34, n. 3, p. 746-754, 2005. 
MICHEL, B. E.; KAUFMANN, M. R. The osmotic potential of poliethylene glycol 6000. Plant Physiology, Bethesda, v. 51, n. 5, p. 914-916, 1973.

NEYA, O. et al. Aging increases the sensitivity of neem (Azadirachta indica) seeds to imbibitional stress. Seed Science Research, Wageningen, v. 14, n. 2, p. 205-217, 2004.

PARIZ, C. M. et al. Qualidade fisiológica de sementes de Brachiaria e avaliação da produtividade de massa seca, em diferentes sistemas de integração lavoura-pecuária sob irrigação. Pesquisa Agropecuária Tropical, Goiânia, v. 40, n. 3, p. 330-340, 2010.

PEREIRA, M. R. R. et al. Efeito de herbicidas sobre plantas de Brachiaria plantaginea submetidas a estresse hídrico. Planta Daninha, Viçosa, v. 28, n. esp., p. 10471058, 2010.
RICHART, A. et al. Desempenho do milho safrinha e da Brachiaria ruziziensis cv. Comum em consórcio. Revista Brasileira de Ciências Agrárias, Recife, v. 5, n. 4, p. 497502, 2010.

RISSO-PASCOTTO, C.; PAGLIARINI, M. S.; VALLE, C. B. Meiotic behavior in interspecific hybrids between Brachiaria ruziziensis and Brachiaria brizantha (Poaceae). Euphytica, Wageningen, v. 145, n. 1, p. 155-159, 2005.

TEKLETSADIK, T. et al. Effect of dry season cutting management on subsequent forage yield and quality of ruzi (Brachiaria ruziziensis) and dwarf napier (Pennisetum purpureum L.) in Thailand. Natural Science, Victoria, v. 38, n. 1, p. 457-467, 2004.

WUEST, S. Vapour is the principal source of water imbibed by seeds in unsaturated soils. Seed Science Research, Wageningen, v. 17, n. 1, p. 3-9, 2007. 